\title{
Discussion on Teaching Pattern of Cultivating Engineering Application Talent of Automation Specialty
}

\author{
Hui Chen ${ }^{1,2}$, Zhanming $\mathrm{Li}^{1,2}$, Wei $\mathrm{Li}^{1,2}$, Haijie Mao ${ }^{1,2}$ \\ 1. School of Electrical \& Information Engineering Lanzhou University of Technology Lanzhou, China \\ 2. Key Laboratory of Gansu Advanced Control for Industrial Processes Lanzhou, China
}

\begin{abstract}
This paper presents some methods to improve teaching pattern of automation specialty to overcome the existing problems in the applications of traditional teaching pattern. These methods include bilingual teaching, class teaching, network teaching and innovation practice teaching. All of these construct a multi-level and stereoscopic teaching pattern, which gives some effective way to cultivate high level creative talented person of automation specialty. The application of the presented teaching pattern in actual teaching practice proves its effectiveness.
\end{abstract}

Index Terms: Automation specialty; teaching pattern; quality education; innovation; stereoscopic teaching

(C) 2012 Published by MECS Publisher. Selection and/or peer review under responsibility of the International Conference on E-Business System and Education Technology

\section{Introduction}

In the 21th Century, how to educate automation engineer of practice application to meet the requirements of advanced manufacturing industry is an important and noteworthy issue for automation educators. Automation is a very hot and characteristic major in china. Its features are: the combination of strong electric and weak electric, the combination of electric technology and electronic technology, the combination of hardware and software, the combination of component and system, the combination of mechanism and control. Its related field is very wide such as professional knowledge and skill about control engineering, elementary knowledge and basic skill about automation and information technology. These contents will educate undergraduate to get a series of actual engineering qualities including computer technology, control technology, network construction, electric and electronic technology, etc. Obviously, undergraduate education of automation should integrate theory with practice and pay more attention to professional quality education. This paper presents some effective education methods, which mainly aim to traditional education defect in automation education and meet the requirements of automation developing trend. These methods are bilingual teaching, class teaching, network teaching, innovation practice teaching, etc. Moreover, teaching process adopts five combinations, which are the combination of mother-tongue teaching and bilingual teaching, the combination of academic frontier and elementary theory, the

This work is supported by the National Professional-level Building Points of China (Grant No. TS12517), the Excellent Young Teachers Program of Lanzhou University of Technology and the Teaching Research Project of Lanzhou University of Technology (Grant No. 201011) in China.

* Corresponding author.

E-mail address: jdch220@sina.com 
combination of theory and engineering application, the combination of research result and teaching content and the combination of class teaching and practice application teaching.

\section{Bilingual teaching pattern}

With China joining WTO, China's economic development already stepped into orbit of economic globalization. It requests many talents who have not only extraordinary knowledge work bottom but also good English communication capability. In 2001, Ministry of Education of China presented implementation of the bilingual teaching to strengthen the undergraduate course teaching and improve the quality of instruction. Under this circumstance, many universities in China are probing a bilingual education pattern suiting themselves. In author's university, some measures are taken to adapt bilingual teaching.

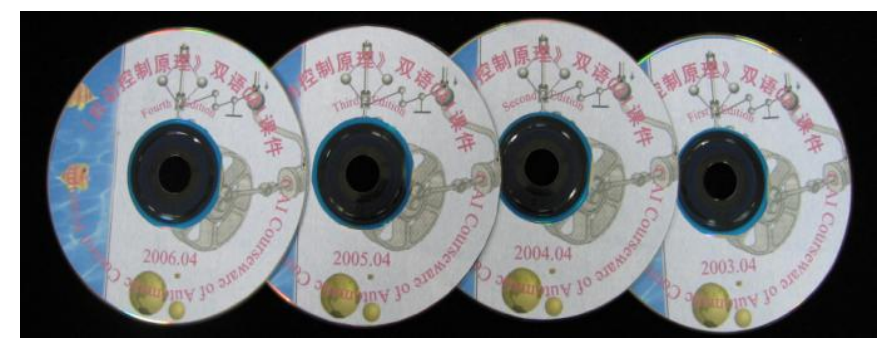

Figure 1. CAI multimedia courseware design

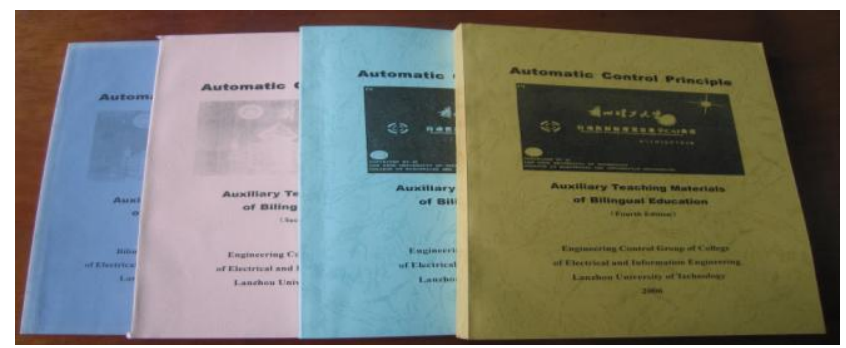

Figure 2. Multimedia courseware handout

From 2001, some English CAI multimedia courseware designed by Authorware 6.5 is introduced into "control theory" class teaching. CD of courseware and course handout is shown in fig.1 and fig.2 respectively. Courseware contents refer to some classical teaching materials including Modern Control Systems [1], Linear Control System Analysis and Design [2] and automatic control theory [3]. As the same time, courseware contents introduce plenty of engineering application examples to deepen undergraduate understanding. And simulate actual system and give relevant demo on line by other program script. It provides a good platform to transform traditional mother-tongue teaching. By this initial pattern, three-dimensional teaching space based on hearing, vision, practice is gradually constructed. It helps to be familiar with bilingual teaching and cultivate good study habit for undergraduate. Work place of author is in west China, educational resources are relatively backward. Through English CAI multimedia courseware gradually extends bilingual teaching circumstance. Then, for those very important concept of course, teacher may give explain in Chinese in order to avoid confusion. Moreover, select some excellent teacher as visiting scholars to go to foreign high-level universities. Thus, improve not only their theory level but also their spoken English level. Hence, other curriculums also have introduced this pattern to take bilingual teaching practice and teaching effect is clearly good. Finally, Submitted exercises need to complete in English. Undergraduate gradually adapts this pattern and get used to express their idea in English. Of course, final examination also needs to be completed entirely in English. 


\section{Practice teaching reform}

Practice teaching is an active and creative course cultivating innovative consciousness in substance. As an important part of major specialty, design independently and increasing practice instruction are inevitable trend. Some measures and ideas are presented in this paper based on practice teaching reform system shown fig.3.

Open lab all the time and give undergraduate more opportunity to design experiment content themselves. First, this increases operation rate of lab and help teacher spend more time guiding experiment dispersed. Then, it will extend their study view and explore their subjective capability for undergraduate. Opening lab may cooperate with enterprise and allow them to use hardware and software resources of lab. Thus, experiment of lab might pay more attention to the application problem of enterprise. Moreover, some actual engineering problems from enterprise can be solved by undergraduate. Obviously, it helps to give undergraduate more self-confidence and more employment opportunities. Moreover, there are practice teaching base set up in enterprise. It introduces undergraduate to production line and deepens their concept.

This paper sets up whole practice teaching reform system. By this system, undergraduate will learn the correct method to solve engineering problem. Moreover, this system helps to improve the quality of good engineering design. Its radical goal is taking undergraduate's education of application practical quality as a core. By these means, exploration spirit, innovative consciousness and comprehensive quality were cultivated respectively.

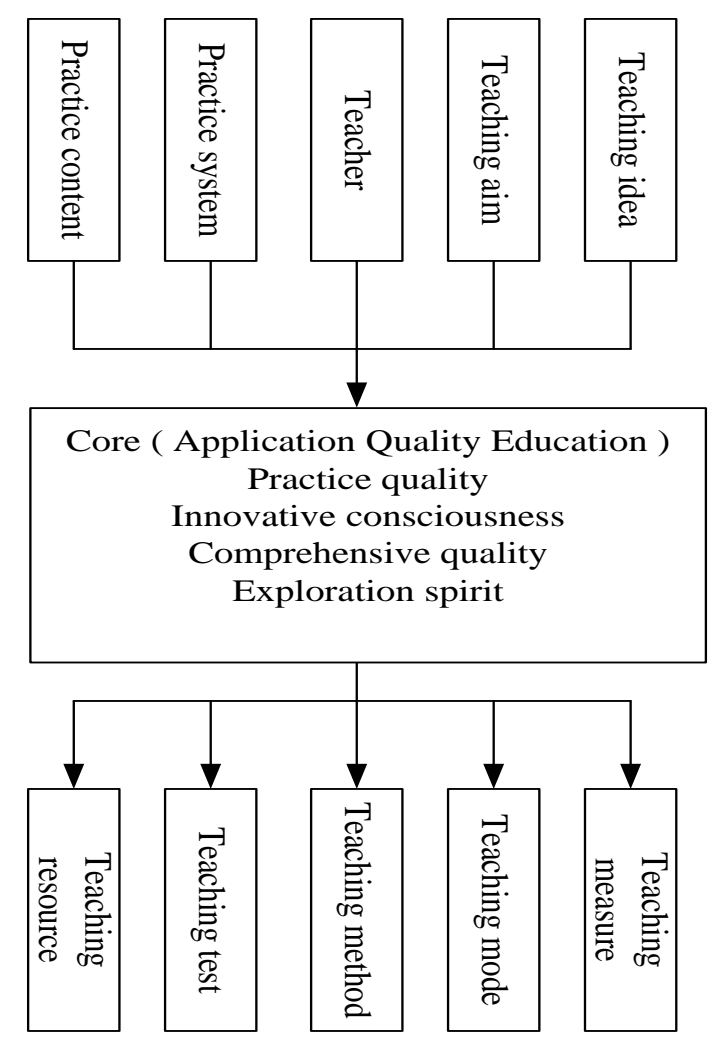

Figure 3. Practice teaching reform system 


\section{The improvement of the second class}

The second class is a beneficial supplement for class teaching. By extracurricular education activities, responsibility, cooperation and competition were improved. Innovative practice quality is correspondingly increased. Guide undergraduate to join technological club and encourage them to complete engineering development in a co-operative manner. Scientific design contest and related academic activities should be widely carried out in the second class. Some knowledge forums and lectures about research frontier were introduced to the second class and extracurricular activities were reasonably occupied by scientific research circumstances. All of these give different level undergraduate more chances to adapt and involve in the associated contents, which will provide a multi-level, multi-aspect personalization space of research.

\section{Stereoscopic pattern construction}

With the advent of information age, teaching method must show diverse and stereoscopic. It includes class teaching, network teaching, innovation practice teaching and preliminary engineering research teaching. For ordinary class teaching, colorful CAI multimedia courseware concerned above need to be extensively introduce. Moreover, network teaching is a very important pattern to extend class teaching. For example, the URL (http://kecheng.lut.cn/zidongkonzhi/index.asp) is a web site link for "Control Theory" course. This web sit is shown fig.4. There are plentiful contents. Undergraduate may get many interesting resources including courseware, exercise submitting system, FAQ system, engineering application example, examination question database, resume of teacher, etc. It is important to note that FAQ system has attracted more attention. The system deeply extends class teaching and shortens the distance among the teachers and the classmates. Undergraduate may leave any message about the course. Teaches or other excellent classmates reply in a short time. All of related people can communicate by this system and freely express their opinion in order to learn knowledge. Another interesting is examination question database shown fig.5. This database is a software system developed by VB 6.0. Auto-generating test paper can be got based on genetic algorithm. It makes the test more objective and gives undergraduate the access to the large exercise databases about course.

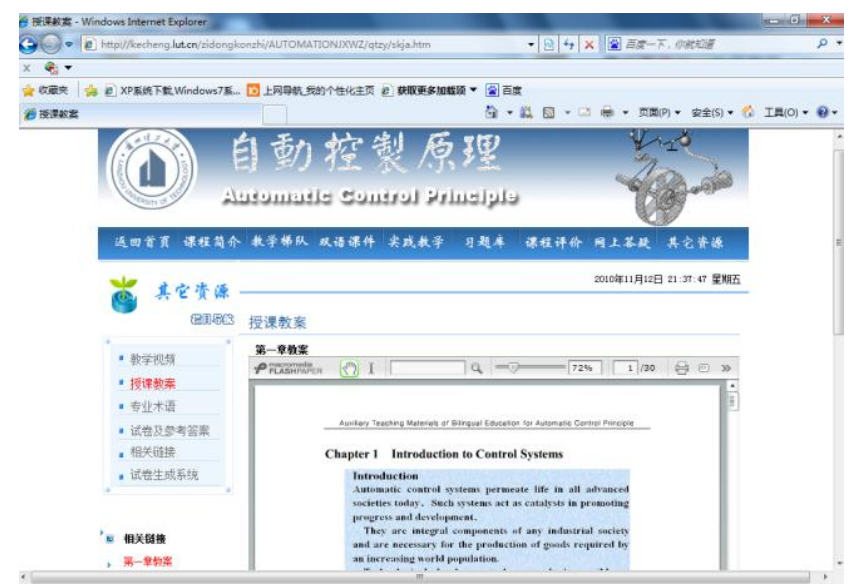

Figure 4. Example of network teaching

Moreover, undergraduate may join the work of network maintenance and construction. Consequently, as a part of the stereoscopic teaching, potential of network teaching is taken full advantage of. 


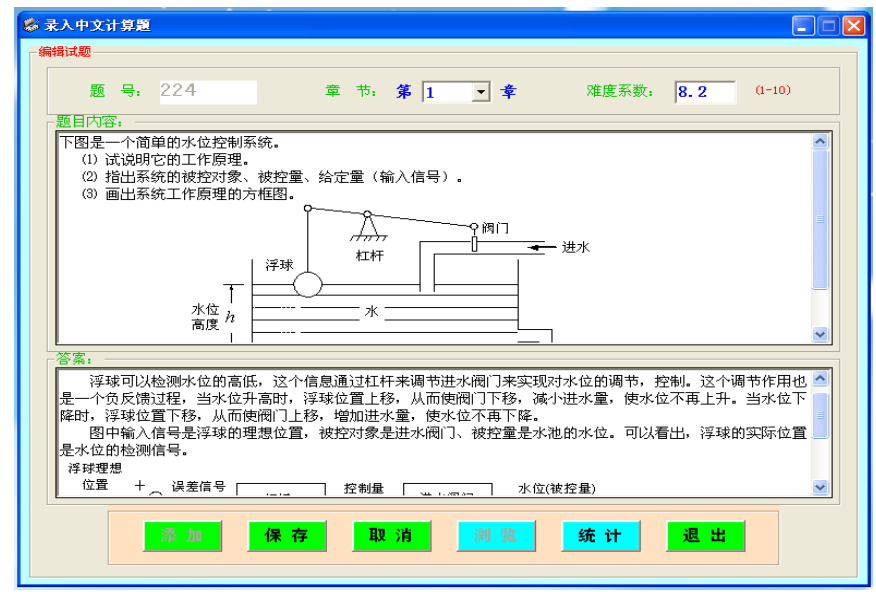

Figure 5. Examination question database

Coordinate with practice teaching base in enterprise concerned above, a nature stereoscopic teaching pattern is constructed undoubtedly.

\section{Conclusion}

This paper presents some methods to improve automation teaching. By this teaching research and application, teachers succeeded in fulfilling themselves not only as a knowledge instructor not only as an engineering partner. Helping each other, sharing resources and creating interactive study space become a reality. It deeply improves study interesting and comprehensive application quality for undergraduate. Moreover, teaching process and teaching effect are reasonably supervised in every teaching aspect. It also helps to listened to the comment from undergraduate and enterprise engineer and summarize the experience to further improve teaching.

\section{Acknowledgment}

Besides those projects listed in footnote, associated work in this paper is sponsored by the National Natural Science Foundation of China (Grant No.61005026) and the Gansu Provincial Science and Technology Planning of China (Grant No. 0916RJZA017).

\section{References}

[1] Richard C. Dorf, Robert H Bishop. Modern Control Systems. Prentice Hall , ISBN-10 / ASIN: 0132270285, 2007, America.

[2] John J. D'Azzo, Constantine H. Houpis, Stuart N. Sheldon. Linear Control System Analysis and Design. McGraw-Hill, ISBN 0-8247-4038-6, America.

[3] Shousong Hu. Automatic control theory. Science press. ISBN: 9787030189554, china. (In Chinese) 